\title{
En veltrent mann med mekanisk aortaklaff og leggsmerter
}

\author{
En mann i 50-årene med mekanisk aortaklaff ble gjentatte ganger vur- \\ dert poliklinisk grunnet smerter fra venstre legg samt en episode med \\ kortvarig synsnedsettelse. Riktig diagnose ble ikke stilt før etter flere \\ uker. Dette gjorde sykdomsforløpet mer alvorlig.
}

Mannen ble henvist akuttmottaket med smerter fra venstre legg. Fire år tidligere var han blitt operert med mekanisk aortaklaff grunnet aortastenose, med postoperativ innsetting av permanent pacemaker grunnet totalblokk. Han var ellers frisk og i god fysisk form og brukte ikke medisiner fast, bortsett fra at han fikk antikoagulasjonsbehandling med warfarin. Tre måneder tidligere var han blitt vurdert på legevakt grunnet smerter fra venstre lår etter trening. Dette hadde man oppfattet som muskelstrekk.

Etter en treningsøkt på tredemølle (dag 0) kontaktet pasienten legevakt på dag 2 grunnet venstresidige leggsmerter, som igjen ble antatt å være muskulært betinget. Dag 5 ble han henvist til sykehus fordi man mistenkte dyp venetrombose på grunn av vedvarende leggsmerter.

Allmenntilstanden var god. Leggen var moderat øm og rød distalt, uten varmeøkning. Han var afebril med et blodtrykk på 146/62 $\mathrm{mm} \mathrm{Hg}$, pulsen var $86 / \mathrm{min}$ regelmessig. Auskultasjon var som ved mekanisk aortaklaff, for øvrig ingen bilyd. Prøveresultater: hemoglobinnivå $13,0 \mathrm{~g} / 100 \mathrm{ml}(13,4-17,0 \mathrm{~g} /$ $100 \mathrm{ml}$, leukocytter $8,6 \cdot 10^{9} / \mathrm{l}\left(4,0-11,0 \cdot 10^{9}\right)$ 1), CRP-nivå $164 \mathrm{mg} / \mathrm{l}(<4) \mathrm{mg} / \mathrm{l}, \mathrm{SR} 96 \mathrm{~mm} / \mathrm{t}$ (< $12 \mathrm{~mm} / \mathrm{t}$ ), INR-verdi 4,2 (0,8-1,2), D-dimer $0,5 \mathrm{mg} / \mathrm{l}(<0,5 \mathrm{mg} / \mathrm{ll}$.

Grunnet høy INR-verdi og lav D-dimer anså man dyp venetrombose som lite sannsynlig. Ved ortopedisk vurdering kunne det ikke påvises akillesseneskade eller annen ortopedisk årsak. Etter konferering med bakvakt ble tilstanden oppfattet som erysipelas eller infisert hematom, som ble behandlet med dikloksacillin.

Pasienten ble sendt hjem fra akuttmottaket til oppfølging hos fastlegen.

Dag 12 ble pasienten på nytt henvist fra fastlegen. Han hadde da vedvarende smerter, hevelse og varmeøkning i samme legg som sist. Han hadde hatt episoder med feber og frostrier, men var ved undersøkelsestidspunktet afebril og i god allmenntilstand, med et blodtrykk på 145/73 mm Hg og regelmessig puls på 70/min.
Blodprøver viste et CRP-nivå på $91 \mathrm{mg} / \mathrm{l}$, leukocytter 9,3 · 10\%/l, INR-verdi 2,8, D-dimer $0,3 \mathrm{mg} / \mathrm{l}$, SR $76 \mathrm{~mm} / \mathrm{t}$, ellers normalt. Auskultasjonsfunn over aortaklaff var som før. Omkretsen av venstre legg var nå $5 \mathrm{~cm}$ større enn høyre, lokalstatus for øvrig var beskrevet som relativt upåfallende, men det var en lett varmeøkning.

Man anså igjen sannsynligheten for dyp venetrombose som liten. Inflammasjonsmarkørene var fallende, og man antok at symptomene skyldtes traume etter trening. Ekkokardiografi eller blodkultur ble ikke vurdert på dette tidspunkt.

Han ble igjen sendt hjem fra akuttmottaket til oppfølging hos fastlegen.

Smertene i leggen forble konstante, og på dag 50 ble pasienten poliklinisk vurdert av ortoped. Den venstre leggen var da kjølig og blek. Man mistenkte arteriell insuffisiens, og pasienten ble henvist til snarlig vurdering hos karkirurg, men rakk ikke å få time der. Han var også $i$ kontakt med øyelege grunnet kortvarig synsnedsettelse på venstre side, uten at man kunne påvise noe patologisk.

Atte uker etter den primære vurdering $i$ akuttmottaket (dag 54) ble mannen innlagt med venstresidig facialisparese med hengende munnvik samt utslettet nasolabialfure. Over hjertet hørtes ventilklikk, som ved mekanisk aortaklaff, og en nyoppstått systolisk bilyd. Temperaturen var $38,3^{\circ} \mathrm{C}$, blodtrykket $135 / 65 \mathrm{~mm} \mathrm{Hg}$, pulsen $82 / \mathrm{min}$ regelmessig. Transtorakal ekkokardiografi viste aortainsuffisiens. CT caput bekreftet mediainfarkt høyre side med beskjeden blødning subaraknoidalt samt mistanke om infarkt også i høyre cerebellum.

Transøsofageal ekkokardiografi bekreftet omfattende forandringer som ved ventilendokarditt med delvis klaffeløsning og stor paravalvulær lekkasje. Det ble tatt blodkulturer og startet opp med antibiotika intravenøst i form av gentamycin, kloksacillin og rifampicin. Tannstatus ble undersøkt og var upåfallende.

Fire dager etter aktuelle innleggelse (dag 58) ble pasienten operert med ny biologisk

\section{Marianne Bjerva*}

bjervamarianne@gmail.com Akuttmedisinsk avdeling Oslo universitetssykehus, Ullevål

Dag Berild

Infeksjonsmedisinsk avdeling Oslo universitetssykehus, Ullevål og Institutt for klinisk medisin Universitetet i Oslo

\section{Dag Jacobsen}

Akuttmedisinsk avdeling Oslo universitetssykehus, Ullevål og Institutt for klinisk medisin Universitetet i Oslo

* Nåværende adresse:

Avdeling for anestesiologi, Akuttklinikken Oslo universitetssykehus, Ullevål 


\section{RAMME 1}

Viktige diagnostiske kliniske manifestasjoner ved endokarditt. Ofte glidende overgang mellom immunkompleksnedslag og septiske embolier

Oslers knuter: Rødlig, ømme knuter eller lesjoner på særlig fingertupper, fotsåler eller øretipp grunnet immunkompleksnedslag. Kan oppstå tidlig eller sent i forløpet av endokarditt

Janeways lesjoner (fig 1): Rødlig, makuløst eller papuløst utslett forårsaket av mikroabscesser og punktblødninger på hånd eller fotsåler. Ikke ømme. Tilheler i løpet av dager til uker

Roths flekker: Hemoragisk blødning lofte med sentral hvit oppklaring) på retina forårsaket av immunkompleksnedslag

Splinterblødning (fig 2): Mindre blødning under neglen, ofte en rett linje. Kan ses ved ulike tilstander og være tegn på mikroembolisering

aortaklaff. Det forelå nærmest komplett løsning av protesering, uten tegn til abscess. Pacemakeren ble fjernet for å sanere et eventuelt infeksjonsfokus. Intraoperativ transøsofageal ekkokardiografi viste velfungerende ny ventil uten paravalvulær lekkasje. Postopera-

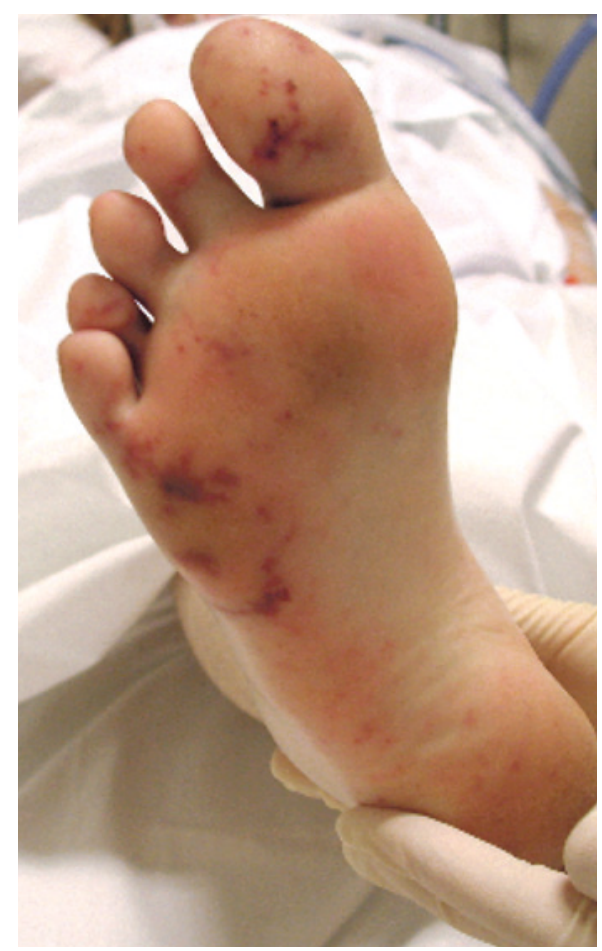

Figur 1 Janeways lesjon tivt var det et ukomplisert forløp med implantasjon av tokammerpacemaker.

Det ble antatt at den nyoppståtte systoliske bilyden var forårsaket av økt hastighet over den defekte ventilen (pendelflow). Kardiolog bekreftet senere også diastolisk bilyd som ved aortainsuffisiens.

Det var oppvekst i blodkultur tatt ved innkomst, i totalt to av 13 flasker etter henholdsvis seks og syv dager, med funn av Propionebacterium acnes fra to ulike innstikkssteder. Dette ble initialt tolket som mulig kontaminasjon, men da også vevsbiopsi fra hjerteklaff viste samme bakterie, ble empirisk antibiotikabehandling endret til benzylpenicillin i monoterapi etter resistensbestemmelse (dosering 1,2 $\mathrm{g} \times 6$ ).

Pasienten ble behandlet med antibiotika intravenøst i totalt 30 dager. Han ble utskrevet $i$ god allmenntilstand, uten motoriske sekveler, unntatt lett dysartri, til videre oppfølging ved slagpoliklinikken.

Han har vært til rehabilitering og er tilbake $i$ arbeid $i$ halv stilling, men han har fortsatt konsentrasjonsproblemer.

\section{Diskusjon}

Infeksiøs endokarditt er en sjelden tilstand (1). I et materiale fra Ålesund, publisert i 2011, fant man over en tiårsperiode en insidens på 6,3/100 000 per år (2). Pasienter som er ventiloperert utgjør $10-30 \%$ av alle tilfeller av infeksiøs endokarditt (3).

Tilstanden var tidligere assosiert med revmatisk feber og rammet særlig yngre voksne med streptokokktonsillitt. På tross av bedring i diagnostikk og behandling har insidensen og mortaliteten (vel 20\%) vært nær uendret de siste 20 år $(1,4)$. Årsaken tilskrives delvis epidemiologiske endringer (4)

I våre dager er risikogruppene injiserende misbrukere samt personer med intravenøse katetre eller elektroder. De øvrige er mennesker med medfødt hjertefeil og en økende andel av eldre med degenerative klaffelidelser eller gjennomgått klaffeplastikk (5). Andre medvirkende faktorer er endring i agens samt antibiotikaresistens.

Sykdomsbildet er ofte preget av uspesifikke og springende symptomer fra ulike organer. Dette gjør diagnostikken vanskelig. Feber ses hos $80 \%$ og bør lede til videre utredning med blodkultur på lav klinisk mistanke hos risikogrupper. Nyoppstått kardial bilyd er rapportert hos $48 \%$ (5). Inflammasjonsprøver er forhøyet hos to tredeler, hvilket var tilfellet hos vår pasient. Leukocytose og anemi er beskrevet hos $50 \%$ (5).

Kutane manifestasjoner er forårsaket av mikroembolier, fokale vaskulitter eller deponering av sirkulerende immunkomplekser. Oslers knuter og Janeways lesjoner på hånd eller fotsåle bør lede til mistanke om immunkompleksdanning og septisk embolisering (6) (ramme 1, fig 1, fig 2). Embolier til retina kan gi synsforstyrrelser, slik som antatt hos vår pasient, og funn av Roths flekker ved oftalmoskopi er en viktig diagnostisk ledetråd. Hematuri og proteinuri er ofte intermitterende og kan være tegn på nyreaffeksjon med deponering av immunkomplekser og septiske embolier (7).

Etter episoden med leggsmerter fikk vår pasient akutt et cerebralt insult, noe som er en fryktet komplikasjon av infeksiøs endokarditt. Cerebrale embolier rammer $10-35 \%$ av pasienter med infeksiøs endokarditt i venstre hjerteside. Ved MR caput vil inntil $80 \%$ ha embolier som ikke er klinisk erkjent (8).

Hos injiserende misbrukere ses manifestasjoner i lunge, som pneumoni eller emboliske abscesser forårsaket av høyresidige vegetasjoner. Sepsis, meningitt og perifere abscesser kan være betinget i infeksiøs endokarditt. Atypiske kliniske manifestasjoner er vanligere hos eldre og hos immunsvekkede pasienter, som ofte kan være afebrile initialt (6). De kliniske tegn kan også være mer diffuse dårlig appetitt, frysninger, vekttap og generell sykdomsfølelse.

Diagnostisering av infeksiøs endokarditt er basert på Dukes modifiserte kriterier, som anses å ha en sensitivitet på nærmere $80 \%$ (3) (ramme 2). Sykdomsbildet kan være akutt og fulminant, især hos injiserende misbrukere (9). Det er imidlertid ikke uvanlig at symptomer og tegn følger et subakutt til kronisk forløp med lavgradig feber og uspesifikke symptomer - som hos vår pasient - en typisk «endocarditis lenta».

Gjeldende retningslinjer anbefaler at pasienter med mekaniske hjerteklaffer følges postoperativt med ekkokardiografi etter to-tre måneder, ett år og ti år. Ny ekkokardiografisk undersøkelse bør tas så lenge det anses som medisinsk hensiktsmessig samt ved utvikling av symptomer eller nye bilyder (10). Vår pasient var fulgt etter disse retningslinjene. Han hadde ikke vært til omfattende tanninngrep etter operasjon.

Det er mulig, men ikke sikkert, at tidligere ekkokardiografi ville ha ført til raskere korrekt diagnose, da pasienten hadde lite symptomer på aktuelle sykdom tidlig i forløpet. Hos risikopasienter anbefales det likevel at blodkultur og transtorakal ekkokardiografi tas på vid indikasjon. Supplerende transøsofageal ekkokardiografi kan bekrefte diagnosen og anses å ha en sensitivitet på 90-95\% (11). Høy sensitivitet til tross - ekkokardiografi kan kun påvise og aldri avkrefte endokarditt.

Infeksiøs endokarditt forårsakes hyppigst av gule stafylokokker og streptokokker, som samlet står for mer enn $80 \%$ av tilfellene, etterfulgt av enterokokker (5). 5-10\% av 


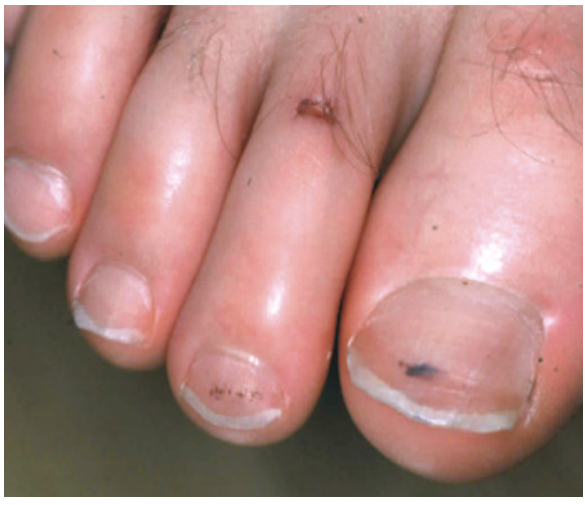

Figur 2 Splinterblødning (negleblødning)

tilfellene er forårsaket av bakterier tilhørende HACEK-gruppen (Haemophilus, Actinobacillus, Cardiobacterium, Eikenella og Kingella), gjærsopp og andre grampositive/ negative bakterier. Dykningsnegativ endokarditt forekommer hos ca. 10\%. Hos injiserende misbrukere er Staphylococcus aureus hyp- pigste årsak. Ved proteseendokarditt innen to måneder etter operasjon dominerer $S$. aureus og koagulasenegative stafylokokker (4). 2-12 måneder postoperativt er alfahemolytiske streptokokker og koagulasenegative stafylokokker hyppigst. Ved sen proteseendokarditt, mer enn ett år etter operasjon, er etiologien som ved native klaffer $(12,13)$.

Propionebacterium, korynebakterier og koagulasenegative stafylokokker tolkes oftest som forurensning, men kan i sjeldne tilfeller være opphav til infeksiøs endokarditt - spesielt hos pasienter med kunstige hjerteklaffer eller inopererte fremmedlegemer (pacemaker/ICD), som hos vår pasient.

Propionebacterium acnes er vanligvis en lavvirulent anaerob bakterie som er del av kroppens hudflora og ofte assosieres til acne vulgaris. Bakterien produserer biofilm, et polysakkaridlag, som gjør den motstandsdyktig mot antibiotika (14). Den kan ligge intracellulært i hvilefase i måneder til år og kjennetegnes ved at den vokser langsomt. I gjennomsnitt tar det 6-7 dager før man får

\section{RAMME 2}

Dukes modifiserte kriterier for infeksiøs endokarditt, gjengitt etter European Society of Cardiology 2015 (3)

\section{Hovedkriterier}

Oppvekst i blodkultur

Typiske bakterier for infeksiøs endokarditt i to ulike blodkulturer uten påvist primærfokus: Streptococcus viridans, Streptococcus gallolyticus (bovis), Staphylococcus aureus, HACEKgruppen, sykehuservervede enterokokker

Persisterende bakteremi

$\geq 2$ positive blodkulturer med $\geq 12$ timers mellomrom

Oppvekst i 3 av 3 eller 3 av 4 blodkulturer (med $\geq 1$ times mellomrom)

Enkel positiv blodkultur for Coxiella burnetii eller lgG-antistofftiter $>1: 800$

\section{Positiv bildediagnostikk}

Typiske ekkokardiografiske funn (vegetasjoner, abscess, pseudoaneurisme, intrakardial fistel, klaffeperforasjon eller aneurisme. Ny partiell løsning av klaffeprotese)

Unormalt opptak sett ved $\mathrm{PET} / \mathrm{CT}$ (dersom protesen var implantert $>3 \mathrm{md}$. tidligere) eller SPECT/CT rundt klaffeproteser

Paravalvulær skade bekreftet med CT hjerte

\section{Tilleggskriterier}

Predisponerende hjertesykdom eller intravenøst stoffmisbruk

Feber, definert som temperatur $>38^{\circ} \mathrm{C}$

Vaskulære funn (inkludert de som kun bekreftes med bildediagnostikk): arteriell embolisme, septisk lungeinfarkt, mykotisk aneurisme, intrakranial blødning, konjunktival blødning, Janeways lesjoner

Immunologiske funn: glomerulonefritt, Oslers knuter, Roths flekker, revmatoid faktor

Mikrobiologiske funn: Oppvekst i blodkultur av bakterier som ikke oppfyller hovedkriteriene eller serologiske funn som bekrefter aktiv infeksjon

Diagnose stilles ved minst to hovedkriterier, ved ett hovedkriterium og tre tilleggskriterier eller ved fem tilleggskriterier

oppvekst i blodkultur. Utvidet dyrkning på aerobt/anaerobt medium kan være nødvendig i inntil tre uker for å få oppvekst (15). Dette medfører at både symptomer og komplikasjonsfaren kan være betydelig når korrekt agens bekreftes.

Med oppvekst i kun to av 13 flasker er det ikke sikkert at en anlagt blodkultur ved de to vurderingene i akuttmottaket ville vært positiv, siden denne bakterien oftest klassifiseres som kontaminasjon. Det er høy risiko for abscessformasjon ved Propionebacterium acnes hos klaffeopererte, men det var ingen abscess $i$ aortaroten hos vår pasient. Antibiotikabehandling alene anses sjelden som tilstrekkelig, og terskelen for kirurgi bør være lav (16).

\section{Konklusjon}

Vår pasient illustrerer et noe atypisk forløp av infeksiøs endokarditt, forårsaket av en sjelden bakterie som bidro til at det tok lang tid før diagnosen ble stilt. I ettertid kan man mistenke at septiske emboluser forårsaket smertene i låret allerede ved første legekontakt. Medvirkende til forsinket diagnostikk kan være at pasienten ble vurdert av forskjellige leger i akuttmottaket. Allmenntilstanden var god, og initialt satte man søkelys på mulig treningsskade og rabdomyolyse, noe som gjorde at endokarditt ikke ble mistenkt.

Hos en pasient med mekanisk aortaklaff og permanent pacemaker med kliniske funn og laboratoriefunn som beskrevet burde man nok på et tidligere tidspunkt ha vurdert endokarditt som mulig diagnose. De initialt høye inflammasjonsmarkørene kan retrospektivt tilskrives hans endokarditt.

Vi anbefaler at man hos denne pasientgruppen også undersøker for eventuelle hudmanifestasjoner, palperer perifere pulser og sjekker tannstatus. Ved mistanke bør man på et tidlig stadium supplere med blodkulturer og (transøsofageal) ekkokardiografi.

Kasuistikken illustrerer at symptombildet ved endokarditt kan være vanskelig å tolke og at tilstanden fortsatt er en av medisinens store imitatorer.

\section{Epilog}

Pasienten har samtykket til - og ønsket gjengivelse av pasienthistorien i Tidsskriftet. Vi har redegjort for - og beklaget - den forsinkede diagnostikken. Han ble orientert om Norsk pasientskadeerstatning, der han har fått erstatning og er blitt vurdert til en uføregrad på $20 \%$ etter det inntrufne.

Pasienten har gitt samtykke til at artikkelen blir publisert. 


\section{Marianne Bjerva (f. 1979)}

er lege i spesialisering i anestesiologi.

Forfatter har fylt ut ICMJE-skjemaet og oppgir ingen interessekonflikter.

\section{Dag Berild (f. 1951)}

er spesialist i indremedisin og i infeksjonssykdommer. Han er overlege og professor i infeksjonssykdommer og arbeider med rasjonell antibiotikabehandling og resistens.

Forfatter har fylt ut ICMJE-skjemaet og oppgir følgende interessekonflikter: Han har mottatt foredragshonorar fra MSD and Astellas.

\section{Dag Jacobsen (f. 1952)}

er spesialist i klinisk farmakologi, i indremedisin og i hjertesykdommer, avdelingsleder og professor.

Forfatter har fylt ut ICMJE-skjemaet og oppgir ingen interessekonflikter.

\section{Litteratur}

Klein M. Wang A. Infective endocarditis. J Intensive Care Med 2016; 31: 151-63.

2. Gulati G, Hole T, Eide E. Infeksiøs endokarditt ved Ålesund sjukehus 1997-2006. Tidsskr Nor Legeforen 2011; 131: 115-7.

3. Habib G, Lancellotti P. Antunes MJ et al. 2015 ESC Guidelines for the management of infective endocarditis. Eur Heart J 2015; 36: 3075-128.

4. Prendergast $\mathrm{BD}$. The changing face of infective endocarditis. Heart 2006; 92: 879-85.

5. Hoen B, Duval X. Clinical practice. Infective endocarditis. N Engl J Med 2013; 368: 1425-33

6. Beynon RP, Bahl VK, Prendergast BD. Infective endocarditis. BMJ 2006: 333: 334-9.

7. Crawford MH, Durack DT. Clinical presentation of infective endocarditis. Cardiol Clin 2003; 21: $159-66, v$

8. Grecu N, Tiu C, Terecoasa E et al. Endocarditis and stroke. Maedica (Buchar) 2014: 9: 375-81.

9. Huseby T, Smith G, Von der Lippe E et al. Infeksiøs endokarditt ved Ullevål sykehus 1988-94. Tidsskr Nor Legeforen 1998; 118: 222-5.

10. Aakhus S, Andersen K, Geiran G et al. Kontroll av pasienter som har gjennomgått klaffekirurgi. Hjerteforum 2010; 23: 1 .

11. Evangelista A, Gonzalez-Alujas MT. Echocardiography in infective endocarditis. Heart 2004; 90 $614-7$

12. Nasjonal faglig retningslinje for bruk av antibiotika i sykehus. Oslo: Helsedirektoratet, 2013.

13. Sjursen H. Antibiotikabehandling ved infeksiøs endokarditt. Tidsskr Nor Lægeforen 2001; 121: $3300-5$.

14. Kurz M, Kaufmann BA, Baddour LM et al. Propionibacterium acnes prosthetic valve endocarditis with abscess formation: a case report. BMC Infect Dis 2014: 14: 105

15. Hinestrosa F, Djurkovic S, Bourbeau P et al. Propionebacterium acnes as a Cause of Prosthetic Valve Aortic Root Abscess. J Clin Microbiol 2007; 45: 259-61.

16. List RJ, Sheikh N, Theologou T et al. Propionebac terium Acnes Endocarditis of a Prosthetic Aortic Valve. Cardiol Clin 2009; 32: E46-7. 